\title{
Relationship between the acylation-stimulating protein gene and coronary heart disease in the Xinjiang Uygur and Han populations of China
}

\author{
Y. Chen ${ }^{1,2}$, Y.T. Ma ${ }^{1}$, S.J. Yang ${ }^{1,2}$, Y.N. Yang ${ }^{1,2}$, Z.Y. Fu ${ }^{1,2}$, X. Xie ${ }^{1,2}$, \\ X.M. Li ${ }^{1,2}$ and Y.Y. Zheng ${ }^{1,2}$ \\ ${ }^{1}$ Department of Cardiology, \\ The First Affiliated Hospital of Xinjiang Medical University, Urumqi, China \\ ${ }^{2}$ Xinjiang Key Laboratory of Cardiovascular Disease Research, Urumqi, China \\ Corresponding author: Y.T. Ma \\ E-mail: myt-xj@163.com / myt_xj@sina.com
}

Genet. Mol. Res. 13 (2): 2638-2644 (2014)

Received June 10, 2013

Accepted December 6, 2013

Published April 8, 2014

DOI http://dx.doi.org/10.4238/2014.April.8.6

\begin{abstract}
The association of the single nucleotide polymorphism $301 \mathrm{~T}>\mathrm{C}$ in the coding region of the acylation-stimulating protein (ASP) gene with coronary heart disease (CHD) was investigated in the Uygur (385 CHD patients and 483 control subjects) and Han (390 CHD patients and 439 control subjects) populations of China. The frequency of the CC and CT genotypes was significantly higher in patients with CHD compared to the control group (55.3 vs 46.2\%, $\mathrm{P}=0.001)$ in the Uygur population, but in the Han population, the frequency was significantly higher in the control group (51.7 vs $24.4 \%, \mathrm{P}<0.001)$. In addition, the $\mathrm{C}$ allele was significantly associated with $\mathrm{CHD}$ in the Uygur population $(\mathrm{C}$ allele: 33.8 vs 26.2\%, T allele: 66.2 vs $73.8 \%$; $\mathrm{P}=0.004)$ and in the Han population (C allele: 14.5 vs $30.3 \%$, T allele: 85.5 vs $69.7 \%$; $\mathrm{P}<0.001$ ). The CC genotype was independently associated with increased risk of coronary artery disease when adjusted for other cardiovascular risk factors [odds ratio $(\mathrm{OR})=2.189,95 \%$ confidence interval $(\mathrm{CI})=1.251$ $3.830, \mathrm{P}=0.001]$ in the Uygur population, but was a protective factor
\end{abstract}


for CHD in the Han population $(\mathrm{OR}=0.373,95 \% \mathrm{CI}=0.187-0.745, \mathrm{P}$ $=0.005)$. In conclusion, the $301 \mathrm{~T}>\mathrm{C}$ polymorphism of the ASP gene that influences the serum triglycerides level in the Uygur population, is associated with the development of CHD, and the CC genotype might be a risk factor of CHD.

Key words: Acylation-stimulating protein; Triglyceride; Han; Uygur; Coronary heart disease

\section{INTRODUCTION}

Epidemiological studies have indicated that the incidence of coronary atherosclerotic heart disease (CHD) is associated with environmental and genetic factors. CHDs are complex disorders. Hypertriglyceridemia (HTG) is a major independent risk factor for diabetes, hypertension, hyperlipemia, and CHD (Frayn, 2001; Redinger, 2008); atherosclerosis, a prominent feature of dyslipidemia, is commonly observed in CHD, and also an independent risk factor of coronary artery disease (CAD). The acylation-stimulating protein (ASP) gene, located in the C3a gene cluster, is an important candidate gene contributing to HTG. ASP results in elevated plasma triglyceride (TG) levels as a non-competitive inhibitor of lipoprotein lipase (LPL), and is the rate-limiting enzyme in TG-rich lipoprotein (TRL) catabolism (Yasruel et al., 1991). Some studies have demonstrated that ASP is the main anabolic stimulator of TG storage in adipose tissue and is produced by adipocytes (Cianflone et al., 2003). ASP stimulates TG synthesis via the ASP receptor, C5L2, a seven-transmembrane G protein-coupled receptor (Kalant et al., 2003, 2005). Several key signaling proteins have been identified downstream of ASP, including phospholipase $\mathrm{C}$, phosphatidylinositol-3 kinase, Akt, and protein kinase $\mathrm{C}$, resulting in increased glucose transport and diacylglycerol acyltransferase activity (Maslowska et al., 2006). ASP is identical to $\mathrm{C} 3 \mathrm{a}$ desArg, and produced through the interaction of the precursor protein $\mathrm{C} 3$, Factor B, and adipsin (also known as Factor D), components of the alternative complement immune pathway, which are secreted by the adipose tissue. The aim of the present study was to determine the frequencies of polymorphisms of the ASP gene in the Chinese Uygur and Han populations in order to investigate the associations with variations in plasma lipid and lipoprotein levels in patients with CHD. Accordingly, homozygotes for risk alleles of the single nucleotide polymorphism (SNP) 301T $>$ C of the ASP gene may have an increased risk of developing CHD.

\section{MATERIAL AND METHODS}

\section{Subjects}

All subjects in the control group (439 Han and 483 Uygur) were unrelated age- and gender-matched individuals who were selected via health screenings at the Outpatient Department of the First Hospital of XinJiang Medical University, Urumqi, China from January 2007 to March 2010; none of the subjects had coronary vascular diseases. The case group consisted of CHD patients ( 385 Uygur and 390 Han) with significant coronary stenosis determined by cardiovascular angiography (according to stenosis $\geq 50 \%$ in at least one coronary artery) at the Department of Endocrinology of the First Hospital of XinJiang Medical University, Urumqi. None of the patients were related. 
The study was approved by the Ethics Committee of the First Hospital Affiliated to Xinjiang Medical University. Neither the patients nor the controls had congenital heart disease, rheumatic heart disease, heart failure, multiple organ failure, or other general illnesses.

\section{Data collection}

The serum concentrations of TG, cholesterol (CHOLC), high-density lipoprotein cholesterol (HDL-C), and low-density lipoprotein cholesterol (LDL-C), as well as blood urea nitrogen (BUN), creatinine (Cr), and uric acid (UA) levels of all subjects were measured with an Automatic Biochemistry Analyzer (Olympus 5400) and a GmbH diagnostic kit (Roche) in the Central Laboratory of the First Affiliated Hospital of XinJiang Medical University.

\section{Genotyping}

Fasting venous blood was collected in 5-mL EDTA tubes, and genomic DNA was isolated with a Pure Gene kit (Gentra Systems Inc.). Sequence information for use as a reference template was obtained from the Ensembl Genome Browser. Sequencing primers were designed using the Primer 5.0 software. The sense primer was 5'-CGCCAGTGAGGCAATGTG-3' and the antisense primer was 5'-CCCAGCGAGGCAGTTCTT-3'. Extraction of genomic DNA from peripheral blood samples was conducted as described previously (Cianflone et al., 2003; Yang et al., 2006). The polymerase chain reaction (PCR) was carried out with $50 \mathrm{ng}$ genomic DNA in a $20 \mu \mathrm{L}$ reaction containing $10 \mu \mathrm{L}$ Power Mix (Beijing Biotech; Beijing, China), 9.5 $\mu \mathrm{L}$ distilled water, and $0.2 \mu \mathrm{L}$ each forward and reverse primer. A Gene Amp 9700 thermal cycler (Applied Biosystems; Foster City, CA, USA) was used for PCR amplification. The program consisted of an initial denaturation step at $95^{\circ} \mathrm{C}$ for $5 \mathrm{~min}, 35$ cycles at $95^{\circ} \mathrm{C}$ for $30 \mathrm{~s}, 56^{\circ} \mathrm{C}$ for $30 \mathrm{~s}$, and $72^{\circ} \mathrm{C}$ for $1 \mathrm{~min}$, followed by a final extension step at $72^{\circ} \mathrm{C}$ for $10 \mathrm{~min}$. A 1615 -base pair (bp) product was amplified and purified using ExoSAP-IT (Amersham Biosciences) according to manufacturer instructions before it was used as a template for sequencing. Sequencing reactions were performed by BGI-Beijing (Beijing, China; http://www.genomics.cn).

The PCR products of the 301T $>$ C polymorphism sites were digested with the restriction enzyme RsaI (Fermentas; Beijing, China) at $37^{\circ} \mathrm{C}$ for $16 \mathrm{~h}$, separated by electrophoresis on $2 \%$ agarose gel, and visualized by ethidium bromide staining. Fragments of $320 \mathrm{bp}$ for the TT wild homozygote (absence of RsaI cutting site) and of 212 and $108 \mathrm{bp}$ for the CC mutant homozygote (presence of $R s a$ I cutting site) were produced. The TC heterozygote showed three fragments of 320, 212, and $108 \mathrm{bp}$ (Figure 1).

\section{Statistical analysis}

All data were analyzed using the SPSS 17.0 software (SPSS; Chicago, IL, USA). Hardy-Weinberg equilibrium was assessed by the chi-square test. Measurement data are reported as means $\pm \mathrm{SD}$, and differences between CHD patients and control subjects were assessed with the independent sample Student's $t$-test. Fasting TG levels were log-transformed using natural logarithms for analyses and are presented as geometric means with the inter-quartile range (25th-75th quartile). Differences in enumeration data between the CHD group and the control group were analyzed using the chi-square test, as the differences in the distributions of genotypes and alleles between the two groups. Logistic regression analyses were used to assess the contribution of the major risk factors. 


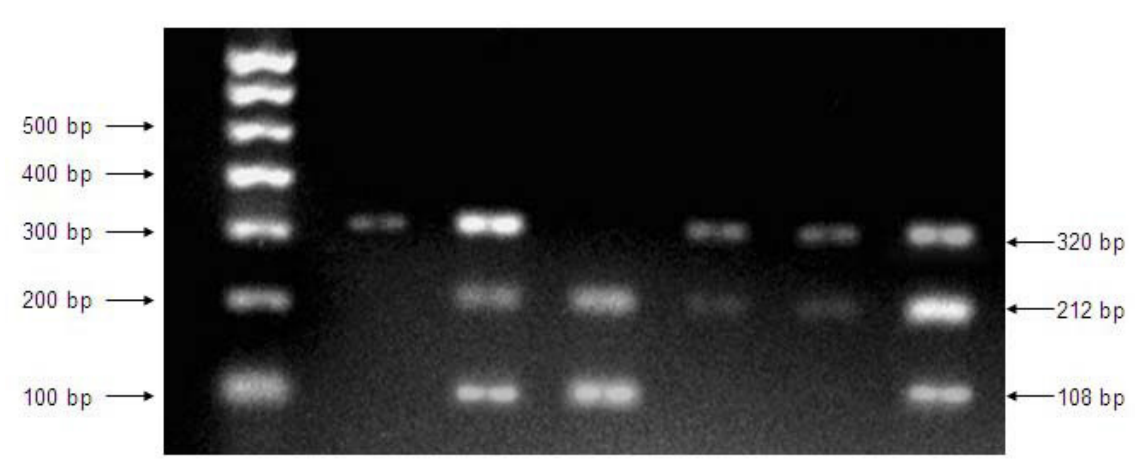

Figure 1. Restriction fragment length polymorphism analysis for genotype determination. CT genotype shows three bands of 320, 212, and $108 \mathrm{bp}(2,4,5$, and 6); CC genotype shows two bands of 212 and 108 bp (3); TT genotype shows one band of $320 \mathrm{bp}(1)$.

\section{RESULTS}

\section{Participant characteristics}

The general characteristics of the study subjects (Han and Uygur) are presented in Table 1. In Han subjects, there were no significant differences in gender, body mass index (BMI), diastolic blood pressure (DBP), TG, UA, and $\mathrm{Cr}$ between the two groups $(\mathrm{P}>0.05)$. However, there were significant differences in age, hypertension, diabetes, smoking, drinking, glucose, CHOLC, HDL-C, LDL-C, and BUN between the two groups $(\mathrm{P}<0.05)$. In Uygur subjects, there were no significant differences in gender and BUA between the two groups $(\mathrm{P}>$ 0.05). However, age, hypertension, diabetes, smoking, drinking, glucose, CHOLC, TG, HDL$\mathrm{C}$, LDL-C, and $\mathrm{Cr}$ values in the two groups were significantly different $(\mathrm{P}<0.05)$.

Table 1. Characteristics of the participants.

\begin{tabular}{|c|c|c|c|c|c|c|c|c|}
\hline & \multicolumn{4}{|c|}{ Han population } & \multicolumn{4}{|c|}{ Uygur population } \\
\hline & Control $(\mathrm{N}=439)$ & $\mathrm{CHD}(\mathrm{N}=390)$ & $\chi^{2}$ or $t$ & $\overline{\text { Pvalue }}$ & Control $(\mathrm{N}=483)$ & $\mathrm{CHD}(\mathrm{N}=385)$ & $\chi^{2}$ or $t$ & $P$ value \\
\hline Age, mean (SD) & $57.91(12.17)$ & $60.71(10.32)$ & -3.532 & 0.000 & $50.42(9.42)$ & $54.65(10.07)$ & -6.367 & 0.000 \\
\hline Gender, female (\%) & $107(24.4)$ & $89(22.8)$ & 0.599 & 0.276 & $90(18.6)$ & $67(17.4)$ & 0.219 & 0.640 \\
\hline Hypertension, N (\%) & $227(52.1)$ & $253(65.0)$ & 14.223 & 0.000 & $113(23.5)$ & $147(38.2)$ & 21.781 & 0.000 \\
\hline Diabetes, N (\%) & $132(30.3)$ & $198(51.0)$ & 36.536 & 0.000 & $68(14.9)$ & $89(23.1)$ & 9.164 & 0.002 \\
\hline Smoking, N (\%) & $167(38.4)$ & $218(55.9)$ & 25.322 & 0.000 & $133(27.7)$ & $218(56.6)$ & 74.079 & 0.000 \\
\hline Drinking, N (\%) & $93(21.4)$ & $135(34.8)$ & 18.257 & 0.000 & $72(15.1)$ & $143(37.2)$ & 64.795 & 0.000 \\
\hline BMI, mean (SD) & $25.62(3.30)$ & $184(37.4)$ & 1.544 & 0.123 & $25.60(3.86)$ & $27.31(4.30)$ & -5.299 & 0.000 \\
\hline SBP, mean (SD) & 134.37 (18.59) & $141.80(31.56)$ & -3.786 & 0.000 & $126.22(16.11)$ & $138.01(27.59)$ & -6.279 & 0.000 \\
\hline DBP, mean (SD) & $84.28(14.44)$ & $85.72(17.735)$ & -1.134 & 0.257 & $80.66(13.63)$ & $84.97(16.78)$ & -4.302 & 0.001 \\
\hline Glucose, mean (SD) & $4.75(0.79)$ & $6.29(2.50)$ & -12.202 & 0.000 & $5.32(1.74)$ & $5.84(2.08)$ & -3.789 & 0.000 \\
\hline $\mathrm{TG}$, mean $(\mathrm{SD})$ & $1.876(1.48)$ & $1.98(1.30)$ & -1.114 & 0.266 & $1.72(1.87)$ & $1.98(1.11)$ & -2.358 & 0.019 \\
\hline TC, mean (SD) & $4.581(1.02)$ & $4.153(1.03)$ & 5.986 & 0.000 & $4.59(1.33)$ & $4.25(0.98)$ & 4.006 & 0.000 \\
\hline HDL-C, mean (SD) & $1.394(0.41)$ & $1.138(0.33)$ & 9.687 & 0.000 & $1.23(0.41)$ & $1.03(0.57)$ & 5.54 & 0.000 \\
\hline LDL-C, mean (SD) & $3.121(0.97)$ & $2.516(0.85)$ & 9.277 & 0.000 & $2.72(0.89)$ & $2.58(0.92)$ & 2.11 & 0.035 \\
\hline $\mathrm{UA}$, mean $(\mathrm{SD})$ & $334.86(95.39)$ & $330.11(86.60)$ & 0.744 & 0.457 & $281.46(89.87)$ & $328.58(81.63)$ & -7.65 & 0.000 \\
\hline $\mathrm{Cr}$, mean (SD) & $74.85(18.81)$ & $77.98(26.31)$ & -1.980 & 0.048 & $73.61(23.68)$ & $77.94(18.93)$ & -2.82 & 0.005 \\
\hline BUN, mean (SD) & $4.997(1.46)$ & $5.330(1.70)$ & -3.021 & 0.003 & $4.98(1.62)$ & $5.15(1.81)$ & -1.428 & 0.154 \\
\hline
\end{tabular}

$\mathrm{BMI}=$ body mass index; $\mathrm{SBP}=$ systolic blood pressure; $\mathrm{DBP}=$ diastolic blood pressure; $\mathrm{TG}=$ triglyceride $\mathrm{TC}=$ total cholesterol; HDL-C = high-density lipoprotein cholesterol; LDL-C = low-density lipoprotein cholesterol; UA $=$ uric acid $; \mathrm{Cr}=$ creatinine; $\mathrm{BUN}=$ blood urea nitrogen $\mathrm{CHD}=$ coronary heart disease. 


\section{Distribution of genotype and allele frequencies of the polymorphic site in the CHD and control groups}

Table 2 shows the genotype and allele distributions of the ASP $(301 \mathrm{~T}>\mathrm{C})$ gene polymorphic site in the study population. The genotype distribution in each group conformed to Hardy-Weinberg equilibrium ( $\mathrm{P}>0.05$ in the $\mathrm{CHD}$ group and the control group). In Han subjects, the frequencies of the $\mathrm{C} / \mathrm{C}, \mathrm{C} / \mathrm{T}$, and $\mathrm{T} / \mathrm{T}$ genotypes of the ASP $(301 \mathrm{~T}>\mathrm{C})$ polymorphism were 4.6, 19.7, and 75.6\%, respectively, in the CHD group, and 8.9, 42.8, and 48.3\%, respectively, in the control group $(\mathrm{P}<0.001)$. The frequency of the $\mathrm{C}$ allele was lower in the CHD group than in control subjects in the Han population $(14.5$ vs $30.3 \%, \mathrm{P}<0.001)$, but the frequency of the $\mathrm{C}$ allele was higher in CHD patients than in Uygur control subjects (33.8 vs $26.2 \%, \mathrm{P}=0.004)$. Furthermore, we found that patients with the $\mathrm{CC}$ genotype had a higher risk of $\mathrm{CHD}(\mathrm{CC} v s \mathrm{TT}$ : $\mathrm{OR}=2.189, \mathrm{P}=0.001,95 \% \mathrm{CI}=1.251-3.830)$ in Uygur subjects. However, in the Han population, the CC genotype showed a protective effect in CHD patients (CC vs TT: $\mathrm{OR}=0.373, \mathrm{P}=0.005,95 \% \mathrm{CI}=0.187-0.745)$ (Table 3). Furthermore, there were significant differences in smoking, hypertension, TG, and HDL-C between the two groups in both the Uygur and Han populations $(\mathrm{P}<0.05)$, as shown in Table 3.

Table 2. Distribution of genotype and allele frequencies of polymorphic site of acylation-stimulating protein gene.

\begin{tabular}{|c|c|c|c|c|c|c|c|c|c|c|}
\hline \multirow[t]{2}{*}{ Group } & & \multirow[t]{2}{*}{$\mathrm{N}$} & \multicolumn{4}{|c|}{ Genotype (N, \%) } & \multirow[t]{2}{*}{$P$} & \multicolumn{2}{|c|}{ Allele (Frequency) } & \multirow[t]{2}{*}{$\mathrm{P}$} \\
\hline & & & $\mathrm{CC}$ & $\mathrm{CT}$ & TT & $\mathrm{CC}+\mathrm{CT}$ & & $\mathrm{C}$ & $\mathrm{T}$ & \\
\hline \multirow[t]{2}{*}{$\overline{\text { Han }}$} & Control & 439 & $39(8.9)$ & $188(42.8)$ & $212(48.3)$ & $227(51.7)$ & \multirow[t]{2}{*}{$<0.001$} & $266(30.3)$ & $612(69.7)$ & \multirow[t]{2}{*}{$<0.001$} \\
\hline & CHD & 390 & $18(4.6)$ & 77 (19.7) & 295 (75.6) & $95(24.4)$ & & $113(14.5)$ & $667(85.5)$ & \\
\hline \multirow[t]{2}{*}{ Uygur } & Control & 483 & $29(6.0)$ & $194(40.2)$ & $260(53.8)$ & $223(46.2)$ & \multirow[t]{2}{*}{0.001} & $252(26.2)$ & $714(73.8)$ & \multirow[t]{2}{*}{0.00} \\
\hline & CHD & 385 & $47(12.2)$ & $166(43.1)$ & $172(44.7)$ & $213(55.3)$ & & $260(33.8)$ & $510(66.2)$ & \\
\hline
\end{tabular}

$\mathrm{CHD}=$ coronary heart disease.

\begin{tabular}{|c|c|c|c|c|c|c|c|c|c|c|c|c|}
\hline & \multicolumn{6}{|c|}{ Uygur } & \multicolumn{6}{|c|}{ Han } \\
\hline & B & S.E. & Wald & $P$ & OR & $95 \% \mathrm{CI}$ & B & S.E. & Wald & $\mathrm{P}$ & OR & $95 \% \mathrm{CI}$ \\
\hline $\mathrm{CC}$ & 0.784 & 0.285 & 7.541 & 0.001 & 2.189 & $1.251-3.830$ & -0.985 & 0.352 & 7.829 & 0.005 & 0.373 & $0.187-0.745$ \\
\hline Smoking & 1.127 & 0.164 & 47.083 & 0.000 & 3.086 & $2.237-4.258$ & 0.751 & 0.172 & 19.182 & 0.000 & 2.121 & $1.515-2.967$ \\
\hline Hpertention & 0.547 & 0.175 & 9.523 & 0.002 & 1.717 & $1.218-2.421$ & 0.526 & 0.175 & 9.075 & 0.003 & 1.693 & $1.202-2.384$ \\
\hline TG & 0.135 & 0.056 & 5.781 & 0.016 & 1.145 & $1.025-1.279$ & 0.308 & 0.087 & 12.555 & 0.000 & 0.735 & $0.620-0.871$ \\
\hline HDL & -0.578 & 0.223 & 6.160 & 0.013 & 0.561 & $0.355-0.855$ & -1.515 & 0.264 & 32.926 & 0.000 & 0.220 & $0.131-0.369$ \\
\hline Constant & 0.688 & 0.394 & 3.052 & 0.081 & 1.991 & & 2.720 & 0.426 & 40.697 & 0.000 & 15.183 & \\
\hline
\end{tabular}

$\mathrm{TG}=$ triglyceride; $\mathrm{HDL}=$ high-density lipoprotein.

\section{DISCUSSION}

This is the first study to evaluate functional polymorphisms of the ASP gene in relation to CHD susceptibility in the Uygur and Han populations of China. The results demonstrated that the 301T $>$ C polymorphism of the ASP gene is significantly associated with an increased risk of CHD in the Uygur population.

Much attention has been focused on the association of genetic polymorphisms with CHD. ASP is increased in diabetes, cardiovascular disease, hyperthyroidism, and polycystic 
ovary syndrome (Yang et al., 2006). Cellular studies have demonstrated that ASP is a main anabolic stimulator of TG storage in adipose tissue and is produced by adipocytes.

ASP stimulates TG synthesis via the ASP receptor, C5L2, a seven-transmembrane G protein-coupled receptor (Cianflone et al., 2003; Kalant et al., 2003). Several key signaling proteins have been identified downstream of ASP, including phospholipase C, phosphatidylinositol-3 kinase, Akt, and protein kinase C (Kalant et al., 2005), culminating in increased glucose transport and diacylglycerol acyltransferase activity (Maslowska et al., 2006). ASP is identical to $\mathrm{C} 3 \mathrm{a}$ desArg and is produced through the interaction of the precursor protein $\mathrm{C} 3$, Factor B, and adipsin (also known as Factor D), components of the alternative complement immune pathway, which are secreted by adipose tissue.

We identified the 301T $>$ C polymorphism and assessed the association between ASP and CHD in the Han and Uygur populations. The frequency of the CC genotype was significantly higher in CAD patients than in control subjects in the Uygur population. However, in the Han group, the frequency of the CC genotype was lower in CAD patients than in control subjects. This indicated that the risk of CHD was increased in Uygur subjects carrying the C allele. After adjustment for other cardiovascular risk factors, logistic regression analyses suggested that compared to the TT genotype, the CC genotype is associated with a higher risk of $\mathrm{CAD}(\mathrm{OR}=2.189, \mathrm{P}=0.001,95 \% \mathrm{CI}=1.251-3.830)$ in the Uygur population. By contrast, in the Han population, the $\mathrm{CC}$ genotype has a higher protective effect for $\mathrm{CAD}$ compared to the TT genotype $(\mathrm{OR}=0.373, \mathrm{P}=0.005,95 \% \mathrm{CI}=0.187-0.745)$.

Lipid disorders are associated with high TG and TC levels; therefore, meals with high levels of saturated fatty acids will obviously increase lipid levels. We found that the TG level was higher in CHD patients than in control subjects in the Uygur population $(\mathrm{P}<0.05)$. Previous studies have found that the main reasons for differences in individual lipid levels are associated with diet structure, financial conditions, and social environment (Linn et al., 1989; Kesteloot et al., 1989). The diet structure of the Uygur population in this study is mainly comprised of mutton and milk, and animal fat accounts for $32 \%$ of the meat intake quantity (He and Zhang, 1989), which may be the principal reason contributing to the high incidence of hyperlipemia in the Xinjiang population of China. Logistic regression analyses suggested that smoking is a high risk factor for CHD in the Han and Uygur populations. Studies have found that smoking has a negative impact on lipids (Handa et al., 1990; Imamura et al., 2000); it can significantly increase HDL-C levels and also the standard level of total cholesterol (Wu et al., 2001).

The results of our study demonstrated that the levels of plasma TG were much higher in patients with the CC genotype in the Uygur population. As previously demonstrated (Cianflone et al., 1989; Sniderman and Cianflone, 1994), the key genes in the conversion of complement $\mathrm{C} 3$ to its ASP form (C3a desArg) are all produced by adipocytes: C3, factor B (FB), adipsin (or factor D), and carboxypeptidase N (CPN1). Genetic polymorphisms may vary among different ethnic groups. In our study population, the frequencies of the $301 \mathrm{~T}>\mathrm{C}$ polymorphism for the CC, CT, and TT genotypes were $6.0,40.2$, and $53.8 \%$, respectively in the control subjects, and were $12.2,43.1$, and $44.7 \%$, respectively in the CHD patients. The genotype frequencies for $\mathrm{CC}+\mathrm{CT}$ genotypes were significantly higher in the CHD group than in the control group (46.2 and 55.3\%, respectively, $\mathrm{P}=0.001$ ). After adjustment for age, gender, smoking, hypertension, diabetes mellitus, and hypercholesterolemia, the $\mathrm{C}$ allele carriers had a higher risk of developing CHD compared to TT homozygotes. It has also been found that ASP is highly expressed in the shoulder regions of advanced atherosclerotic lesions, which suggested that this potent matrix-degrading enzyme also contributes to plaque instability. Similar 
to the findings of Fallah et al. (2010), we did not find any significant effect of the 301T $>C$ polymorphism on the number of diseased vessels in the Uygur population.

In conclusion, this study suggests that the ASP $301 \mathrm{~T}>\mathrm{C}$ polymorphism could be associated with susceptibility to CHD in the Uygur and Han populations of China, and that $301 \mathrm{C}$ allele carriers might be at high risk of developing CHD in the Uygur population. This result may broaden the knowledge of genetic variants and disease-association studies. Undertaking genome-wide association studies in different populations certainly deserves investigation.

\section{ACKNOWLEDGMENTS}

Research supported by the Xinjiang Autonomous Region Science and Technology Projects (grant \#201233138).

\section{Conflicts of interest}

The authors declare no conflict of interest.

\section{REFERENCES}

Cianflone KM, Sniderman AD, Walsh MJ, Vu HT, et al. (1989). Purification and characterization of acylation stimulating protein. J. Biol. Chem. 264: 426-430.

Cianflone K, Xia Z and Chen LY (2003). Critical review of acylation-stimulating protein physiology in humans and rodents. Biochim. Biophys. Acta 1609: 127-143.

Fallah S, Seifi M and Samadikuchaksaraei A (2010). Risk of coronary artery stenosis in Iranian type 2 diabetics: is there a role for matrix metalloproteinase-3 gene (-1612 5A/6A) polymorphism? J. Physiol. Biochem. 66: 359-364.

Frayn KN (2001). Adipose tissue and the insulin resistance syndrome. Proc. Nutr. Soc. 60: 375-380.

Handa K, Tanaka H, Shindo M, Kono S, et al. (1990). Relationship of cigarette smoking to blood pressure and serum lipids. Atherosclerosis 84: 189-193.

He BX and Zhang JY (1989). Dietaty Habits and Longevity Along the Silk Road. In: New Horizons in Preventing Cardiovascular Diseases (Strasser T and Yamori Y, eds.). Elsevier, Amsterdam, 89-93.

Imamura H, Uchida K and Kobata D (2000). Relationship of cigarette smoking with blood pressure, serum lipids and lipoproteins in young Japanese women. Clin. Exp. Pharmacol. Physiol. 27: 364-369.

Kalant D, Cain SA, Maslowska M, Sniderman AD, et al. (2003). The chemoattractant receptor-like protein C5L2 binds the C3a des-Arg77/acylation-stimulating protein. J. Biol. Chem. 278: 11123-11129.

Kalant D, MacLaren R, Cui W, Samanta R, et al. (2005). C5L2 is a functional receptor for acylation-stimulating protein. J. Biol. Chem. 280: 23936-23944.

Kesteloot H, Geboers J and Joossens JV (1989). On the within-population relationship between nutrition and serum lipids: the B.I.R.N.H. study. Eur. Heart J. 10: 196-202.

Linn S, Fulwood R, Rifkind B, Carroll M, et al. (1989). High density lipoprotein cholesterol levels among US adults by selected demographic and socioeconomic variables. The Second National Health and Nutrition Examination Survey 1976-1980. Am. J. Epidemiol. 129: 281-294.

Maslowska M, Legakis H, Assadi F and Cianflone K (2006). Targeting the signaling pathway of acylation stimulating protein. J. Lipid Res. 47: 643-652.

Redinger RN (2008). The prevalence and etiology of nongenetic obesity and associated disorders. South Med. J. 101: 395-399.

Sniderman AD and Cianflone K (1994). The adipsin-ASP pathway and regulation of adipocyte function. Ann. Med. 26: 388-393.

Wu DM, Pai L, Sun PK, Hsu LL, et al. (2001). Joint effects of alcohol consumption and cigarette smoking on atherogenic lipid and lipoprotein profiles: results from a study of Chinese male population in Taiwan. Eur. J. Epidemiol. 17: 629-635.

Yang Y, Lu HL, Zhang J, Yu HY, et al. (2006). Relationships among acylation stimulating protein, adiponectin and complement C3 in lean vs obese type 2 diabetes. Int. J. Obes. (Lond) 30: 439-446.

Yasruel Z, Cianflone K, Sniderman AD, Rosenbloom M, et al. (1991). Effect of acylation stimulating protein on the triacylglycerol synthetic pathway of human adipose tissue. Lipids 26: 495-499. 